\title{
ESTÁGIO OBRIGATÓRIO NÃO PRESENCIAL NO ENSINO DE HISTÓRIA: INQUIETAÇÕES DE ESTUDANTES ANTES E DURANTE A PANDEMIA DO NOVO CORONAVÍRUS
}

\author{
MANDATORY INTERNSHIP IN HISTORY TEACHING: STUDENTS CONCERNS \\ BEFORE AND DURING THE NEW CORONAVIRUS PANDEMIA
}

Cintia Lima Crescêncio ${ }^{1}$

\begin{abstract}
RESUMO: Este artigo tem como objetivo realizar uma reflexão sobre as preocupações de estudantes estagiários(as) do Curso de Licenciatura em História, da Universidade Federal de Mato Grosso do Sul (UFMS), Campus de Três Lagoas (CPTL), antes e durante a pandemia do novo coronavírus. São utilizados como fontes os relatórios de estágios dos anos de 2017, 2018 e 2019, e documentos produzidos pela Comissão de Estágio (COE) durante o período de suspensão dos estágios e de retomada de forma não presencial, no ano de 2020. Estes documentos revelam uma crescente compreensão do ofício docente como prática que se dá no espaço da escola e com a comunidade escolar, entendimento que foi acelerado pelo contexto de suspensão de atividades presenciais.
\end{abstract}

Palavras-chave: Estagiários(as). Ensino remoto. Saberes docentes.

\begin{abstract}
This article aims to reflect on the concerns of trainee students of the History Degree Course, at the Federal University of Mato Grosso do Sul (UFMS), Três Lagoas Campus (CPTL), before and during the new coronavirus pandemic. Internship reports from the years 2017, 2018 and 2019 are used as sources, as well as documents produced by the Internship Committee (COE) during the period of suspension of internships and non-face-to-face resumption, in 2020. These documents reveal a growing understanding of the teaching profession as a practice that takes place in the school and with the school community, wich was accelerated by the context of suspension of face-to-face activities.
\end{abstract}

Keywords: Trainnes. Remote teaching. Teaching knowledge.

1 Doutora em História pela Universidade Federal de Santa Catarina. Professora na Universidade Federal de Mato Grosso do Sul. 


\section{Introdução}

No segundo semestre de 2018, durante reunião do Estágio Obrigatório I, do Curso de Licenciatura em História, da Universidade Federal de Mato Grosso do Sul (UFMS), Campus de Três Lagoas (CPTL), componente curricular que se dedica à observação da escola, das aulas e do projeto político pedagógico da escola, uma turma de estudantes demonstrou um olhar bastante crítico e até mesmo, raivoso, sobre a universidade. Enquanto líamos o livro Ensinando a Transgredir, de Bell Hooks (2013), os(as) estudantes frequentaram as escolas como observadores(as), o que resultou em uma visão quase generalizada de que a universidade não os(as) prepara para a sala de aula. Não havia descontentamento com as disciplinas de referência e conteúdo, mas sim com as práticas e estágios que, na visão deles(as), não os(as) preparavam para salas de aula. Para os(as) estagiários(as), a universidade não os(as) formava para serem professores(as) de História e a visão que prevalecia era que a entrega do diploma, depois de quatro anos, deveria vir acompanhada do domínio pleno dos saberes necessários. Apesar de Bell Hooks (2013) apontar a sala de aula como lugar de trabalho coletivo, em que todos(as) devem tomar posse do conhecimento, a expectativa era que as disciplinas de práticas de ensino, as disciplinas pedagógicas e os estágios dariam conta do "domínio" da sala de aula. Tudo mudou no primeiro semestre de 2020 e as experiências de estágio foram confrontadas com novos desafios.

O contexto da pandemia do novo coronavírus ocasionou o cancelamento de calendários acadêmicos na maior parte das universidades públicas brasileiras, sendo que algumas poucas optaram pela suspensão das aulas presenciais e manutenção do calendário acadêmico. Foi o caso da Universidade Federal De Mato Grosso do Sul - UFMS que, por meio da Portaria No 405, de 16 de março de 2020, autorizou e implementou o que chamou de "teletrabalho", garantindo o prosseguimento do ano letivo (UFMS, 2020b). As atividades práticas também tiveram autorização para serem substituídas, decisão que ficou a critério dos(as) dirigentes das unidades setoriais e coordenadores(as) de curso. O Curso de Licenciatura em História da UFMS/CPTL solicitou a suspensão dos estágios obrigatórios, por entender que sua realização era impossível. A suspensão foi permitida pela instituição e a Comissão de Estágio (COE) instaurou amplo debate entre orientadores(as) de estágio e estudantes, construindo reflexões e 
documentos que registram discussões, inquietações e sugerem caminhos para a situação de excepcionalidade imposta pela pandemia. No segundo semestre de 2020, os Estágios Obrigatórios I, II e III do Curso foram retomados, na modalidade não presencial, sendo regidos pelo Plano de Educação Mínima (PEM), que

[...] visa minimizar os danos e as perdas causados pela realização dos estágios em contexto não presencial, através do levantamento de dados, bibliografia, propostas de execução e diretrizes para que orientadores(as) e estudantes qualifiquem as experiências de estágio [...] (UFMS, 2020a, p. 2).

É sobre o encontro destes dois cenários, de inquietações em relação às práticas de estágio pré pandemia, e de realização de estágios não presenciais durante a pandemia, que este artigo pretende debruçar-se, com o objetivo de realizar uma reflexão sobre as preocupações de estudantes em relação aos estágios obrigatórios no contexto anterior e durante a pandemia do novo coronavírus. Para isso são explorados como documentos: 1. Relatórios de Estágio Obrigatório I, II e III, especialmente do I, dos anos de 2017, 2018 e 2019, que possibilitam uma reflexão sobre o olhar dos(as) estagiários(as) sobre a universidade e sobre as práticas de estágio ofertadas por ela, no momento de ingresso na escola como professores(as) ${ }^{2} ; 2$. Documentos elaborados durante as discussões promovidas pela $\mathrm{COE}$, por ocasião dos debates que decidiram pela retomada dos estágios na modalidade não presencial, especialmente formulários que levantaram as preocupações em relação à realização dos Estágios Obrigatórios I, II e III e que integram o PEM $^{3}$. Para qualificar essa reflexão, este texto propõese a debater o papel dos estágios na formação inicial de professores(as) de História e os impactos da pandemia, na visão dos(as) estagiários, nesta formação.

2A organização e levantamento destes relatórios integra projeto de pesquisa intitulado O Estágio Obrigatório no Ensino de História, coordenado pela autora deste artigo, Cintia Lima Crescêncio, e desenvolvido na mesma instituição. O objetivo do projeto é refletir sobre as experiências de estágio do Curso e qualificar o trabalho de orientação. A sistematização e tabulação dos dados referentes aos relatórios é de autoria da estudante de graduação Isabela Regagnan.

30 Plano de Educação Mínima foi elaborado e desenvolvido pelos(as) integrantes da Comissão de Estágio do Curso de História, em 2020: os(as) professores(as) Cintia Lima Crescêncio (presidenta), Vitor Wagner Neto de Oliveira(coordenador) e Mariana Esteves de Oliveira; e contou com a contribuição dos orientadores(as) de estágio do referido Curso: os(as) professores(as) Leandro Hecko, Dolores Puga, Fortunato Pastore, Luiz Carlos Bento e Henry da Silva, bem como com a contribuição da professora Ligiane Silva, do Curso de Pedagogia da mesma instituição. 
Os relatórios permitem elaborar um diagnóstico sobre uma das principais inquietações de estudantes de licenciatura, pois a preocupação com a sala de aula é uma constante, principalmente entre aqueles(as) que estão no início da graduação. Transmutando os relatórios em fontes, uma vez que desde os anos 1990 os relatórios de estágio são uma interessante fonte de pesquisa sobre a formação e a prática do(a) professor(a) de História (RIBEIRO, 2015), é possível ler e escutar estagiários (as) sobre o que os(as) espanta, o que é ordinário, suas compreensões sobre ensino de História (SEFFNER, 2017) e, certamente, suas visões sobre a formação que a universidade oferece. Os textos que integram o PEM permitem ler e escutar esses(as) mesmos(as) estagiários(as), mas submetidos(as) às relações com orientadores(as), coordenação, a própria instituição da qual são parte, e ao contexto da pandemia, que impactou a visão sobre as atividades de estágio do Curso.

$\mathrm{Na}$ primeira parte do artigo, é realizada uma análise sobre o papel desempenhado pela universidade na formação para a sala de aula. Tal discussão é feita a partir dos relatórios de estágio. Na segunda parte, é elaborada uma reflexão sobre as preocupações dos(as) estudantes com os estágios obrigatórios na modalidade não presencial. Com estas ponderações, foi possível levantar a hipótese que, apesar do difícil contexto imposto pela pandemia às escolas e às universidades, especialmente aos cursos de licenciatura, os estágios passaram por um processo de valorização por parte dos(as) estudantes do Curso de História da UFMS/CPTL.

\section{Os estágios obrigatórios do Curso de Licenciatura em História antes da pandemia}

Em 2002, o Ministério da Educação (MEC) ampliou a carga horária dos cursos de licenciatura sob o argumento de que havia certo desequilíbrio entre disciplinas teóricas e componentes de prática pedagógica. Essa mudança veio acompanhada da demanda que as disciplinas voltadas para o ensino tivessem início nos primeiros anos do curso, atacando de forma direta o modelo que propunha três anos de disciplinas de conteúdo, somados a um ano de disciplinas voltadas para o ensino. Nos cursos de História, tal reformulação tinha como 
objetivo enfraquecer a separação-hierarquia entre bacharelado/licenciatura e pesquisa/ensino de história (NASCIMENTO, 2013, p. 36-42).

O sistema 3+1 funcionava, mas descontentava os/as estudantes e aos próprios professores universitários envolvidos com a formação docente. No primeiro caso, estudantes reclamavam de estudar 3 anos de disciplinas ligadas exclusivamente à história e depois frustravam-se com as cadeiras de formação de professores que tomavam mais um ano da formação, com temas e questões técnicas, estrutura e gestão educacional afastadas de toda especialização acadêmica anterior [...] Um outro elemento negativo desse sistema e que revela muito bem o tipo de egresso que formamos está no equívoco de acreditar que para ser bom professor basta o domínio da área do conhecimento específico que se vai ensinar (NASCIMENTO, 2013, p. 42).

A desestabilização deste modelo, que privilegiava os conteúdos em detrimento de habilidades pedagógicas, causou alteração nas grades curriculares das licenciaturas em História de todo o país, quando disciplinas de didática, práticas e estágios supervisionados foram reforçadas, reconfiguradas, ampliadas (RIBEIRO, 2015), o mesmo vale para o Curso de Licenciatura em História da UFMS/CPTL.

Atualmente o Curso conta com os conteúdos de dimensões práticas/disciplinas Estágio Obrigatório I, II e III, sendo o I de observação da escola, o II de regência no Ensino Fundamental e o III de regência no Ensino Médio. O Estágio I pode ser realizado desde o $3^{\circ}$ semestre do Curso e, idealmente, os três estágios são cumpridos no $3^{a}, 4^{0}$ e $5^{0}$ semestre. Sendo o curso de oito semestres, os estágios podem ser cumpridos muito antes da finalização da graduação. Apesar do caminho trilhado em direção a um saudável equilíbrioarticulação entre disciplinas de conteúdo/pesquisa e práticas pedagógicas, os relatórios de Estágio Obrigatório I, que resumem as primeiras impressões sobre a escola, e mesmo sobre a universidade, demonstram a frequente preocupação de futuros(as) professores(as) iniciantes na articulação entre o que se aprende na universidade e o que se vivencia no espaço da escola.

O contato com este espaço fez com que me sentisse despreparada para a prática da docência, ao observar tantos alunos cada qual com sua especificidade me fez pensar se conseguirei criar ferramentas de ensino que atendam a necessidade de todos estes alunos (ESTUDANTE 1, Relatório de Estágio 1, 2019). 
Diante disso, destaca-se a distância existente entre a teoria aprendida dentro da universidade, todo o conteúdo estudado e absorvido, da prática dentro da sala de aula (ESTUDANTE 2, Relatório de Estágio 1, 2018).

Tais preocupações são evidentes, também, nas reuniões de estágio, especialmente do Estágio Obrigatório I, que não conta com atividades de regência, e expressam-se nos medos e anseios descritos nos relatórios, evidenciando preocupação com a dissociação entre conhecimentos adquiridos/construídos/acessados na universidade e a escola.

O Curso conta, ainda, com cinco conteúdos/disciplinas de Prática de Ensino e Pesquisa em História (PEPHs), que são ministradas desde o $1^{0}$ semestre do curso, são elas: Prática de Ensino e Pesquisa em História: Multiculturalismo, Povos Indígenas e Diversidade; Prática de Ensino e Pesquisa em História: Aspectos Epistemológicos; Prática de Ensino e Pesquisa em História: O Uso de Fontes Históricas em Projetos; Prática de Ensino e Pesquisa em História: Planejamento, Linguagens e Novas Tecnologias e Prática de Ensino e Pesquisa em História: Livro Didático, Trabalho de Campo e Avaliação da Aprendizagem. Do $1^{0}$ ao $8^{\circ}$ semestre do curso, as PEPHs convivem e dialogam com conteúdos de formação específica/disciplinas ${ }^{4}$. Os estágios e as PEPHs são, portanto, fundamentais na formação dos(as) estudantes do Curso, compartilhando o mesmo status das disciplinas exclusivamente de pesquisa e conteúdos específicos da História. Ainda assim, a preocupação dos(as) estagiários(as) é constante e muitas expectativas são colocadas sobre os estágios.

O estágio possibilita o encontro entre a teoria e a prática geralmente não contemplado nas disciplinas dos cursos de licenciatura (ESTUDANTE 3, Relatório de Estágio 1, 2018).

O momento do estágio obrigatório é um momento chave para o estudante, pois esse é o momento onde a teoria encontra com a prática, algo pouco visto nos estudos de história, onde sua maior parte se torna teórica (ESTUDANTE 4, Relatório de Estágio 1, 2019).

\footnotetext{
4A grade curricular do Curso conta, ainda, com cinco conteúdos/disciplinas de formação pedagógica, ministradas por docentes do Curso de Pedagogia.
} 
Mesmo com disciplinas dedicadas a práticas de ensino e pesquisa em História, que visam articular docência e pesquisa, é sobre os estágios que orbita a possível solução de problemas relacionados ao ser professor(a).

O chão da sala de aula é central porque "Para ensinar História não basta, por suposto, possuir conhecimentos históricos, ter alguma formação pedagógica ou conhecer algo de psicologia da aprendizagem" (CAIMI, 2015, p. 112). Os(as) estudantes têm clareza que nosso ofício é composto por uma série de saberes, mas são taxativos(as) ao informar que o saber principal não é apre(e)ndido na sala de aula da universidade. Os estágios são identificados como muito relevantes, ao mesmo tempo que são apontados como momento de descoberta da falta de preparo. A importância dos estágios fica evidentemente reforçada no contexto da pandemia, quando os(as) estudantes demonstram preocupação com a qualidade das suas experiências e os impactos de atividades práticas não presenciais em sua futura atuação profissional, sempre pensada no contexto da escola enquanto instituição que existe fisicamente. Este cenário fica bem delineado nas páginas seguintes, nas reflexões sobre as preocupações com os estágios não presenciais.

A mudança de 2002, que foi também o primeiro passo para implementação de programas de estímulo à docência, através do incentivo à formação de professores(as), como o Programa Institucional de Bolsa de Iniciação à Docência (PIBID) e o Programa de Residência Pedagógica, programas federais desenvolvidos no Curso de História da UFMS/CPTL, é vista e sentida no projeto pedagógico, no currículo e no dia a dia do Curso. Aliadas às preocupações expressadas nos relatórios de estágio, há também estudantes que afirmam não apenas a importância da formação acadêmica, como também a inevitável articulação entre o que se aprende na universidade e o que se vive-aprende na escola.

A partir das minhas observações, penso que, aos poucos, os discursos acadêmicos têm sido vinculados à prática, pois percebi esse esforço no referencial e planejamento da professora de história que observei (ESTUDANTE 5, Relatório de Estágio 1, 2017).

Os referenciais bibliográficos, juntamente com as observações em sala de aula, possibilitaram a construção de uma consciência que articula teoria e a prática (ESTUDANTE 6, Relatório de Estágio 1, 2018). 
As preocupações que acompanham a ruptura da condição de estudantes, para a condição de professores(as) aprendizes, marca do estágio I, de observação, indicam alguma insatisfação com a universidade e, especificamente, com o Curso, embora articulada a um nítido caminho de descoberta da complexidade dos saberes que marcam o fazer docente. Tanto que os relatórios de Estágio Obrigatório II e III, de regência, indicam um olhar mais tranquilo sobre o "fazerse professor(a)".

\begin{abstract}
As aulas de didática, psicologia da educação, sociologia do ensino, as inúmeras práticas de ensino e de pesquisa em história, bem como os grandes debates sobre métodos de aprendizagem ou discussões historiográficas, tornam-se discussões tímidas quando nos deparamos com o desafio de 'enfrentarmos' o dia-a-dia de uma sala de aula (ESTUDANTE 7, Relatório de Estágio 2, 2018).

O curso de História na Universidade Federal de Mato Grosso do Sul propõe em sua grade curricular uma abordagem que integra conteúdos históricos e pedagógicos. Mesmo com tanto aporte que o curso proporciona, as vezes a teoria nunca é o bastante para a prática (ESTUDANTE 8, Relatório de Estágio 3, 2019).
\end{abstract}

Relatórios de Estágio Obrigatório I demonstram mais urgência na solução da articulação entre o que é aprendido na universidade e o que se encontra na escola, já os relatórios de Estágio Obrigatório II e III, momento de regência, apontam uma compreensão mais elaborada da noção de saberes docentes. Talvez esta fase seja de percepção da profissão como ofício não acabado, fechado. A categoria de saberes docentes aponta a pluralidade de saberes necessários ao profissional da História, extrapolando, em grande medida, a premissa de que um conhecimento vasto de conteúdos de História, e mesmo de práticas pedagógicas, é suficiente para a docência no ensino básico.

Bittencourt (2008) relembra que, além de acionar os saberes da disciplina, o(a) professor(a) mobiliza os saberes curriculares, os saberes da formação profissional e os saberes da experiência. Sendo assim, apesar da prática docente ser uma ação solitária, ela é também coletiva. Marlene Rosa Cainelli (2008) concorda com essa pluralidade, mas ao desenvolver pesquisa sobre o conceito de tempo $\operatorname{dos}(a s)$ estudantes, a partir de experiências de estágio, afirma a forte relação entre ação pedagógica e a compreensão da ciência de referência do(a) 
professor(a). E mais, Cainelli (2008) aponta que os(as) estagiários(as) consideram os saberes escolares como saberes menos importantes, se comparados aos saberes científicos necessários à formação profissional, e identifica que, na própria formação, saberes ligados à prática pedagógica são negligenciados em benefício da ciência de referência.

As conclusões de Cainelli (2008), de algum modo, são um termômetro importante para refletir sobre a visão $\operatorname{dos(as)~estudantes~de~História~sobre~os~}$ saberes acadêmicos e os saberes escolares na UFMS/CPTL, no contexto anterior à pandemia. A partir dos relatórios, não é possível identificar os saberes escolares como saberes negligenciados, pelo contrário, há uma preocupação permanente com a articulação destes saberes com os saberes históricos, e um cuidado e uma preocupação constante com os "usos" destes saberes na escola, na prática docente: "Esta ferramenta [experiência de estágio] permite que o aluno tenha contato com a prática docente em si, olhando a docência fora do olhar teórico, e a experimentando fora dos livros (Estudante 9, Relatório de Estágio 2, 2019)". Talvez este seja um sinalizador importante sobre o "sucesso" parcial do Curso em equilibrar-articular saberes múltiplos.

Olavo Pereira Soares (2012) questiona: Em que medida a formação inicial influencia a prática docente? Como os(as) professores(as) reinterpretam a teoria depois do contato com o cotidiano escolar? E mais, que impactos o contato virtual com o cotidiano escolar, imposto pela suspensão das atividades presenciais, recairão sobre estudantes já temerosos(as) em entrarem em salas de aula na condição de professores(as) iniciantes?

Jörn Rüsen discute que, antes da afirmação da História como ciência, foram debatidas as regras e os princípios da composição da História, como problemas de ensino e aprendizagem. A ideia da Historia Vitae Magistra, da antiguidade até o século XVIII, demonstra que a escrita da História era orientada pela moral e pelos problemas práticos da vida, e não por questões teóricas ou empíricas da cognição metódica. Já no século XIX, a História não se pensou como enraizada a necessidades sociais orientadas a partir do tempo e abandonou a reflexão sobre a didática da história e sua função no mundo. A reflexão sobre a didática foi, então, substituída pela discussão metodológica (RÜSEN, 2011, p. 8). Este marco, de algum modo, ainda orienta a História hoje e tem efeitos diretos no ensino de 
História e, consequentemente, nos(as) futuros(as) professores(as). O modelo 3+1 citado anteriormente, é exemplo disso. Mesmo diante da construção da didática da História, o autor identifica que ao "didatizar" a disciplina, ela foi "empurrada" para a pedagogia, movimento que anula as especificidades da área (RÜSEN, 2011, p. 12). Debate recente, contudo, insistiu na originalidade da disciplina e na necessidade desse debate ser feito dentro do próprio campo.

Assim a originalidade básica do pensamento histórico guiou $\mathrm{O}$ problema prático da formulação de um novo currículo de história. A didática da história juntou os assuntos orientados pela prática sobre ensino e aprendizagem em sala de aula com uma percepção teórica dos processos e funções da consciência histórica em geral (RÜSEN, 2011, p. 12).

Rüsen aponta a categoria de consciência histórica como fundamental para o ensino de História, e para o próprio ser e estar no mundo, e destaca que "O que deve ser relembrado aqui é que o ensino de história afeta o aprendizado de história e o aprendizado de história configura a habilidade de se orientar na vida e de formar uma identidade histórica coerente e estável" (RÜSEN, 2011, p. 16). Para o autor, a didática da História, ou a ciência do aprendizado histórico, pode mostrar $\mathrm{a}(\mathrm{o})$ historiador(a) as conexões entre História, vida prática e aprendizado. É essencial, portanto, que estagiários(as) atentem a tais articulações, lançando um olhar crítico para a universidade, mas também entendendo-se como protagonistas no processo de construção da consciência histórica de estudantes de ensino fundamental e médio. Relatórios fruto de experiências de regência demonstram o trilhar dessa trajetória no Curso e a inevitável transversalidade de saberes que se mostram necessários já nas experiências de estágio, bem como a transversalidade entre ciência histórica e aprendizado, muito embora emerja um olhar que, muitas vezes, aponta a universidade como lugar da teoria e a escola como lugar da prática.

O 'fazer-se docente' é tido como uma construção continua e diária na prática desta profissão, e para um graduando do curso de História é essencial a oportunidade de praticar toda a teoria aprendida até então (ESTUDANTE 10, Relatório de Estágio 3, 2018).

Inspirado por Rüsen, Rafael Saddi destaca que a didática da história alemã alterou não apenas a qualidade da reflexão didático-histórica e o campo de 
interesse das pesquisas brasileiras, como também lançou um desafio para a prática docente de História em sala de aula. O pressuposto desse desafio seria que "a consciência histórica é passível de ser transformada/formatada no interior do ambiente escolar" e para isso não poderia haver separação entre teoria e prática, aprendido e ensinado - como a ideia bastante criticada de transposição didática sugere (SADDI, 2016, p. 116). Maria Auxiliadora Schmidt reforça:

$\mathrm{Na}$ perspectiva ruseniana, a relação intrínseca entre consciência história e vida prática remete, necessariamente, à compreensão de como a ação humana no presente está matizada pelas determinações das diferentes dimensões da cultura histórica: a dimensão cognitiva, estética, política, ética e moral, dependendo da abrangência dessas dimensões na formação da consciência histórica dos agentes (SCHMIDT, 2016, p. 33).

Trata-se de relação complexa e rizomática entre ciência de referência e ensino de História. Ao propor que a História faça sentido para a vida prática de crianças e jovens aprendizes, o autor também nos relembra que os cursos de História e seus conteúdos devem fazer sentido à vida prática e profissional dos(as) futuros(as) professores(as) de História. Os saberes acadêmicos, nesse sentido, precisam ser compreendidos como fundamentais e importantes para estagiários(as) que, muito em breve, atuarão em salas de aula como professores(as) regentes. Em função disso, reflexões dedicadas à visão dos(as) estagiários(as) sobre as relações entre universidade e escola, são urgentes, principalmente quando temos no horizonte a premissa que se fazer professor(a) é um processo contínuo (TARDIF, 2000) e que, certamente, depende das experiências na escola e com a comunidade escolar. No contexto da pandemia, entretanto, a escola e a comunidade escolar virtualizaram-se e as preocupações de estagiários(as) multiplicaram-se.

\section{Preocupações em relação aos estágios no contexto da pandemia}

Diante das urgências do ensino e da pesquisa, agora nos vemos diante de atividades de estágio realizadas através da intermediação de telas. A escola assumiu "novas formas" e as experiências de estágio passam a ser marcadas por grupos de Whatsapp e reuniões por Google Meet. As preocupações e anseios de 
estudantes, do contexto anterior à pandemia, são agravadas por experiências de estágio que, mesmo organizadas e baseadas na realidade atual, não são a garantia de atividades práticas que, até o início do ano de 2020, eram vistas com olhar bastante crítico e desconfiado pelos(as) estudantes, mas também como elementares na formação de futuros(as) professores(as) de História. Se relatórios de estágio dos anos de 2017, 2018 e 2019 indicam as preocupações na articulação entre os saberes aprendidos na universidade e o contexto escolar, que preocupações habitam os horizontes de estagiários(as) de História no contexto da pandemia? Impossibilitados(as) de sentir muros, cheiros e ruídos escolares, a previsão é que o olhar preocupado dos(as) estagiários(os) de observação agravese, e que a maturidade de estagiários(as) regentes frente à complexidade dos saberes docentes desestabilize-se, mas também siga um curso de valorização das atividades práticas, o que pode ser observado nas preocupações de estudantes em relação à realização dos estágios obrigatórios na modalidade não presencial.

Estágio Obrigatório não presencial no ensino de História? O que parecia impossível, foi materializado e está em curso no segundo semestre de 2020 na Licenciatura em História da UFMS/CPTL. Às preocupações de anos anteriores, quando nem os estágios pareciam suficientes para sanar as angústias causadas pela responsabilidade de uma sala de aula de ensino fundamental e médio, foram somadas ao sumiço repentino, e esperamos momentâneo, da escola enquanto materialidade, lugar de encontro, de conflito, de afeto, de aprendizado.

Em reunião de 19 de maio de 2020, a COE do Curso de Licenciatura em História da UFMS/CPTL definiu, depois de inúmeras reuniões entre estudantes, orientadores(as) e coordenação de Curso, pela manutenção da suspensão dos estágios obrigatórios por todo primeiro semestre de 2020, informando que "ao invés de dar prosseguimento a experiências de estágio improvisadas" pretendia "planejar os Estágios Obrigatórios I, II e III a serem realizados em 2020/2, de modo a qualificar as experiências docentes, sejam elas remotas ou presenciais" (UFMS, 2020a, p. 6). A decisão, tomada depois de consulta a estudantes, não foi unânime, uma vez que havia evidente preocupação com a perda de qualidade das experiências de estágio, ao mesmo tempo que era presente a ansiedade com atraso de formaturas e cumprimento de créditos. 
Estudantes de Estágio Obrigatório I, que até 2019 preocupavam-se com a inefetividade do ensino acadêmico considerado exclusivamente teórico, comprovada pela entrada nas escolas e salas de aula como professores(as) estagiários(as), viram-se confrontados(as) com a possibilidade dessas experiências sequer existirem. O que observar, se toda observação baseia-se na existência da escola, de agentes, de relações? Estudantes de Estágio Obrigatório II e III, que entram nas salas de aula como regentes, viram-se diante de inúmeras impossibilidades: de prepararem sequências didáticas como aprenderam, prevendo atividades diagnósticas com uso de cartolinas, cadernos, a lousa, discussões, texto, jogos; de explorarem conceitos a partir de questionamentos no começo da aula, face a face com a turma. Viram-se ainda incapazes de utilizar as tecnologias da informação para o ensino e aprendizagem.

Como indicam Cerezer e Fonseca (2015), os(as) estagiários acreditam que os estágios são um momento fundamental na formação de futuros(as) professores(as), por propiciarem um contato concreto e realista com o espaço de atuação profissional. Os relatórios de estágio II e III reforçam nitidamente essa tendência, e sem as ressalvas feitas pelos relatórios de observação. A possibilidade dessa experiência excluir a vivência material e cotidiana na escola tornou-se evidente nas reuniões com estagiários(as) e, especialmente, na pesquisa levada adiante pela COE.

Entre 9 e 17 de junho de 2020, a COE difundiu, através de e-mail, Whatsapp e redes sociais, a pesquisa intitulada "Estágio Obrigatório I, II e III - Curso de História UFMS/CPTL - Levantamentos e subsídios", apresentada da seguinte maneira, via formulário do Google Docs:

Este formulário tem como objetivo principal levantar dados para subsidiar a Comissão de Estágio (COE) no planejamento das estratégias dos Estágios Obrigatórios I, II e III do Curso de História da UFMS/CPTL no prosseguimento curricular do próximo semestre. Solicitamos que as alunas e os alunos o respondam desde que estejam matriculadas(os) ou que pretendam se matricular em algum dos Estágios Obrigatórios ofertados pelo curso no segundo semestre de 2020, considerando que, para tanto, tenham cumprido (ou estejam cumprindo) o pré-requisito de cursar a disciplina Fundamentos de Didática.

A pesquisa foi atendida por 39 estudantes. Destes, 46,2\% iriam realizar pela primeira vez o Estágio Obrigatório I (de observação), ou seja, não tinham realizado 
nenhum estágio, inclusive estudantes matriculados(as) no primeiro semestre de 2020, uma vez que os estágios foram suspensos em função da pandemia. $41 \%$ iriam realizar o Estágio Obrigatório II (de regência) e 12,8\% iriam realizar o Estágio Obrigatório III (de regência) (UFMS, 2020a). Os dados da pesquisa expressam, majoritariamente, a visão de estudantes que nunca realizaram regência, aproximando-se mais, em termos comparativos, das visões de relatórios de estágio I.

As questões foram formuladas a partir das reuniões realizadas entre docentes, entre docentes e discentes e de conversas com discentes do Curso. Professores(as) da rede pública de Três Lagoas também foram consultados(as) informalmente. As questões tinham objetivos diversos, desde mapear dados pessoais, compreender a disponibilidade para realização dos estágios de maneira não presencial, avaliar a relação entre estagiários(as) e escolas durante a suspensão das aulas, identificar o domínio e acesso a tecnologias digitais. Para este artigo interessa-nos, especialmente, as questões que revelam a posição dos(as) estudantes quanto a viabilidade de realização dos estágios obrigatórios através de ensino não presencial e rastrear as preocupações dos(as) estudantes em relação à realização dos estágios neste formato.

Quantitativamente, 47,1\% dos(as) estudantes de estágio afirmaram não se sentir em condições de realizar os estágios obrigatórios enquanto perdurar as medidas de isolamento e ensino "remoto". 28,5\% acreditam que se sente preparado(a) para realização dos estágios apenas observando e registrando as atividades realizadas de forma remota. $14,7 \%$ acreditam ser possível a realização dos estágios por meio de observação e regência, através de atividades não presenciais e contribuindo na mediação tecnológica. Quase metade dos(as) estudantes não se sente em condições de realizar atividades do estágio no contexto imposto pela pandemia, enquanto a outra metade acredita que está preparada para realizar os estágios (UFMS, 2020a).

Perguntados "Qual sua maior preocupação em relação à realização dos estágios nesta conjuntura?" 31 estudantes expressaram opiniões diversas, mas muito focadas na preocupação com a qualidade da experiência.

Estudante 1: Todas! Não sinto que fazendo o acompanhamento remoto estaríamos realizando o estágio. 
Estudante 2: A dificuldade de acesso dos alunos as atividades, e também a nossa própria formação, já que o estágio presencial é fundamental para nossa formação.

Estudante 3: Minha maior preocupação em relação à realização dos estágios nesta conjuntura é a falta de qualidade e a não contribuição para minha experiência profissional

Estudante 4: No futuro não termos tanta segurança para encarar uma turma presencialmente.

Estudante 5: Que as atividades não possam ser bem desenvolvidas e aproveitadas.

Estudante 6: Não ter um resultado bom tanto para os alunos aprenderem, quanto para nós estagiários termos experiência de darmos aulas, pois aulas não presenciais não tem o mesmo efeito quanto as presenciais.

Estudante 7: A perda de parte da experiência de sala de aula. Algo não difícil em ensino remoto.

Estudante 8: A contribuição para a minha experiência profissional. Estudante 9: Não ter um bom aproveitamento da experiência, já que até mesmo os professores das escolas de ensino básico estão encontrando dificuldades em se adequar a nova realidade.

Estudante 10: Minha maior preocupação é não ter um ensino de qualidade, devido a pandemia. (UFMS, 2020a, p. 18-19)

Entre poucas inquietações com a saúde mental, a disponibilidade das escolas e supervisores(as) em aceitar estagiários(as) neste contexto difícil e o atraso na finalização do curso, sobressaem-se as preocupações relacionadas ao importante papel dos estágios durante a graduação.

Os relatórios de estágio de anos anteriores indicam aflições em relação ao ensino ofertado para a prática docente em História. Tais preocupações emergem no momento de entrada na escola e na sala de aula, por meio de estágios de observação. A possibilidade de exclusão dessas experiências, provocadas por estágios não presenciais, são evidentes. Muito embora o estágio seja, muitas vezes, temido e/ou rejeitado, desprezado em favor da excelência da produção do saber histórico propriamente dito (RIBEIRO, 2015), ele é visto como fundamental pelos(as) estudantes. Insinuando, inclusive, uma forte valorização e respeito pela formação pedagógica. Nos relatórios de estágio anteriores à pandemia e na pesquisa no contexto pandêmico, estudantes não indicaram preconceitos de formação. Relatórios de estágio, e fontes que narram as preocupações com a realização de estágios não presenciais, anunciam a qualidade das experiências de estágio como preocupação central dos(as) estudantes do Curso. 
Em provocativo texto intitulado "O que precisa saber um professor de História?", Flávia Caimi (2015) aponta a complexa rede de interveniências protagonizadas por diferentes atores sociais, gestores, mercado editorial, docentes, famílias, estudantes, e tantos outros, com as quais futuros(as) professores(as) de História precisam aprender a lidar, sendo que

\begin{abstract}
Ao fim e ao cabo, a escola precisa contar com professores que conheçam bem os fundamentos de sua disciplina e que saibam comunicá-la aos jovens, para fazê-los pensar historicamente. Dentre os desafios essencialmente relevantes que conformam a história escolar, podemos enumerar, sinteticamente, as tarefas de interrogar os distintos contextos contemporâneos em uma perspectiva histórica, de interpretar esses contextos com o aporte da metodologia histórica e de construir a consciência cidadã sob a perspectiva da História (CAIMI, 2015, p. 122).
\end{abstract}

Nas disciplinas de práticas de ensino e pesquisa, nos estágios obrigatórios, bem como nos Programas de formação de professores(as), o Curso de História da UFMS/CPTL vem se dedicando e aperfeiçoando no árduo desafio de articulação entre saberes construídos/aprendidos/acessados na universidade e saberes construídos/aprendidos/acessados na escola, mesmo consciente de que o ser professor(a) é, entre outras coisas, resultado de prática cotidiana, permanente e da soma destes saberes. Os conhecimentos necessários a um(a) professor(a), portanto, seguem como motivadores e alvos centrais do Curso, justificando um cenário de preocupação, demonstrado pelos relatórios de estágio dos anos de 2017, 2018 e 2019, e de preocupação e valorização, evidente na pesquisa realizada durante a pandemia. Em contexto difícil, o ofício do(a) professor(a) de História passa por visível processo de enaltecimento e admiração, especialmente por estagiários(as). Tudo acompanhado das novas preocupações que emergem.

Atualmente, somamos aos conhecimentos e às tarefas do(a) professor(a) de História, as inúmeras habilidades exigidas por estudantes, famílias, gestores(as) que, de suas casas, pensam e organizam a "sala de aula" no contexto da pandemia. Que estágios são possíveis neste contexto? Que novas inquietações essa "interrupção" virtual nos estágios obrigatórios inaugurou?

Breno Carvalho, em texto de 2014, diagnostica que o "ofício do historiador não sofreu nenhum abalo estrutural por conta das novas tecnologias. $E$ nem corre o risco de extinguir-se. Nada perto disso" (CARVALHO, 2014, p. 183). Se insistimos 
com a premissa que ser historiador(a) é ser professor(a) de História, esse diagnóstico foi solapado pela pandemia do novo coronavírus. Em 2020, nos vimos, como historiadores(as), dialogando com pares através de aplicativos de reuniões virtuais, dependendo exclusivamente da Internet para acessar fontes, utilizando Whatsapp para organizar eventos. Mais do que nunca, como pontua o próprio autor, podemos acompanhar conferências e palestras de especialistas do mundo inteiro, distante geograficamente e economicamente: "A transmissão virtual, em tempo real, não raro com possibilidade para intervenções, tem globalizado experiências e quebrado antigos paradigmas de acesso aos principais centros produtores de conhecimento do mundo" (CARVALHO, 2014, p. 174).

\begin{abstract}
A educação a distância, a digitalização de acervos históricos, os avançados algoritmos matemáticos empregados em buscas documentais, plataformas de compartilhamento de dados e informações, o universo da programação, dos aplicativos, tudo isso é um terreno ainda pouco percorrido pelo profissional de história. Não necessariamente precisamos ser historiadores- programadores, como disse Emmanuel Le Roy Ladurie. Mas é preciso estar atento às novas competências e habilidades que podem ser úteis no fazer história (CARVALHO, 2014, p. 182-183).
\end{abstract}

O que era um recurso em 2014, tornou-se a única saída para historiadores(as) em 2020 e tudo indica que estamos trilhando um caminho sem volta, ao menos parcialmente. Como professores(as) de História, seja do ensino básico ou superior, vimos nossas aulas convertidas a gravações de áudio ou vídeo, pdfs infinitos, transmissões que são insistentemente chamadas de "lives". Fomos apresentados(as) ao conceito de atividade síncrona e assíncrona, comum a docentes habituados ao EaD, mas não à massa de professores(as) de escola e da universidade pública brasileiras. Nossas salas de aula e tudo que as caracterizam, como as relações docente-discente, foram reduzidas a e-mails, grupos de Whatsapp, interações por redes sociais e "aulas virtuais". Tudo fruto de extremo improviso, infelizmente. Se não fomos abalados(as) antes pelas novas tecnologias, tudo indica que estamos sendo agora e uma geração de estudantes de História, realizando disciplinas de conteúdos específicos, mas também de didática, práticas e estágios, estão no olho do furacão. Apesar da posição, estes(as) estudantes indicam uma permanente valorização das atividades práticas do Curso, o que pode sublinhar, também, um processo de valorização de professores(as), de salas de 
aulas, das escolas, sempre apontados como a salvação do país, mas nunca tratados como tal.

\section{Considerações Finais}

Este artigo tinha como foco refletir sobre as preocupações de estudantes estagiários(as) do Curso de Licenciatura em História da UFMS/CPTL antes e durante a pandemia do novo coronavírus, quando a instituição definiu que mesmo as atividades práticas deveriam ser desenvolvidas por meio do "ensino remoto". Essa proposta surgiu de maneira inesperada, interrompendo um projeto que visa refletir sobre as experiências de estágio do Curso e, por sua vez, qualificar o trabalho de orientadores(as) de estágio. Como resposta ao tempo presente, este artigo procurou debater sobre o papel dos estágios na formação inicial de professores(as) de história, pautado nos impactos que a pandemia causou nas experiências de estágio de observação e regência.

Através de relatórios de estágio de anos anteriores, especialmente dos relatórios resultantes das experiências do Estágio Obrigatório I, foi possível observar a permanente inquietação de estudantes no que se refere ao preparo que a universidade oferta com disciplinas teóricas, práticas e didáticas. Para eles(as), a articulação entre os conhecimentos adquiridos/construídos/acessados na universidade e a realidade das escolas é frágil, prevalecendo uma visão que os quatro anos da licenciatura deveriam prepará-los(as) - sem surpresas - para a sala de aula. Os relatórios dos Estágios Obrigatórios II e III, de regência, indicam a mesma preocupação, mas apontam maior maturidade e crença que o fazer-se professor(a) é fruto da prática e de saberes diversos, muito embora a teoria tenha papel central nisso.

Consciente dessa articulação, a COE do Curso suspendeu os estágios no primeiro semestre de 2020, quando as aulas presenciais foram também suspensas pela UFMS e substituídas por atividades remotas. Por entender que as atividades de estágio não poderiam ser improvisadas, em função dos prejuízos que isso poderia causar na formação de estudantes de licenciatura em história, professores(as) e alunos(as) debateram e discutiram o destino dos estágios no contexto da pandemia. Os estágios foram retomados no segundo semestre de 
2020, a partir de amplo planejamento que resultou no PEM, documento que, entre outras coisas, reúne informações sobre as preocupações de estudantes com estágios em modalidade não presencial. Tal levantamento identificou que os(as) estudantes mantiveram como foco de atenção a inquietação com a qualidade das experiências de estágio, insinuando positivamente um processo de valorização das atividades práticas, de professores(as), da sala de aula e das escolas.

Relatos de estudantes, seja nos relatórios, seja nos dados sistematizados por ocasião da organização dos estágios na pandemia, indicam uma crescente compreensão do ofício do(a) professor(a) como exercício de prática e reunião de saberes múltiplos, entendimento que, talvez, tenha sido acelerado pelo difícil contexto imposto pela suspensão das atividades presenciais. Um olhar lançado aos relatórios de observação permitem supôr, também, algum nível de valorização dos saberes acadêmicos, uma vez que a universidade, especificamente a COE e os(as) orientadores de estágio, tiveram papel central na promoção e efetivação dos estágios de forma não presencial, ação ainda em curso. Outras possibilidades poderão ser levantadas a partir de 2021, quando relatórios de estágio finalizados não se dedicarão a narrar e refletir sobre a materialidade de escolas e salas de aula, mas sim sobre sua virtualidade.

\section{Referências}

BITTENCOURT, Circe Maria Fernandes. Ensino de história: fundamentos e métodos. São Paulo: Cortez, 2008.

CAIMI, Flávia Eloísa. O que precisa saber um professor de História?. História \& Ensino, Londrina, v. 21, n. 2, p. 125-150, jul./dez. 2015. DOI 10.5433/22383018.2015v21n2p105. Acesso em: 15 jan. 2021.

CAINELLI, Marlene Rosa. Os saberes docentes de futuros professores de história: a especificidade do conceito de tempo. Currículo sem fronteiras, [s. I.], v. 8, n. 2, p. 134-147, jul./dez. 2008. Disponível em: https://www.curriculosemfronteiras.org/vol8iss2articles/cainelli.pdf. Acesso em: 15 jan. 2021.

CARVALHO, Bruno Leal Pastor de. Faça aqui o seu login: os historiadores, os computadores e as redes sociais online. Revista História Hoje, São Paulo, v. 3, n. 5, p. 165-188, 2014. Disponível em: https://rhhj.anpuh.org/RHHJ/article/view/126/100. Acesso em: 15 jan. 2021. 
CEREZER, Osvaldo Mariotto; GUIMARÃES, Selva. Professores de história iniciantes: entre saberes e prática. História \& Ensino, Londrina, v. 21, n. 2, p. 125 150, jul./dez. 2015. Disponível em: http://www.uel.br/revistas/uel/index.php/histensino/article/view/23855._Acesso em: 15 jan. 2021.

HOOKS, Bell. Ensinando a transgredir: educação como prática da liberdade. São Paulo: Editora WMF Martins Fontes, 2013.

NASCIMENTO, Álvaro Pereira. Mil horas para quê?: a prática como componente curricular na licenciatura em história. Antíteses, Londrina, v. 6, n. 12, p. 35-52, jul./dez. 2013.2 Disponível em: http://www.uel.br/revistas/uel/index.php/antiteses/article/view/17179. Acesso em: 15 jan. 2021.

RIBEIRO, Renilson Rosa. Entre textos e práticas: ensino de história, instituição escolar e formação docente. História \& Ensino, Londrina, v. 21, n. 2, p. 151-179, jul./dez. $2015 . \quad$ Disponível em: http://www.uel.br/revistas/uel/index.php/histensino/article/view/23856/17743. Acesso em: 15 jan. 2021.

RÜSEN, Jorn. Jörn Rüsen e o ensino de história. Curitiba: Ed. UFPR, 2011.

SADDI, Rafael. O Estado de suspensão na aprendizagem histórica: a força estética do conhecimento histórico na instauração de um momento sublime de consciência histórica. Revista História Hoje, São Paulo, v. 5, n. 9, p. 113-130, 2016. Disponível em: https://rhhj.anpuh.org/RHHJ/article/view/247. Acesso em: 15 jan. 2021.

SCHMIDT, Maria Auxiliadora. Jovens brasileiros, consciência histórica e vida prática. Revista História Hoje, São Paulo, v. 5, n. 9, p. 31-48, 2016. Disponível em: https://rhhj.anpuh.org/RHHJ/article/view/232. Acesso em: 15 jan. 2021.

SEFFNER, Fernando. De fontes e mananciais para o ensino de história. In: RODRIGUES, R. R. (org.). Possibilidades de pesquisa em história. São Paulo: Contexto, 2017. p. 243-264.

SOARES, Olavo Pereira. Os currículos para o ensino de história: entre a formação, o prescrito e o praticado. Antíteses, Londrina, v. 5, n. 10, p. 613-634, jul./dez. 2012. Disponível em: http://www.uel.br/revistas/uel/index.php/antiteses/article/view/13319. Acesso em: 15 jan. 2021.

TARDIF, Maurice. Saberes profissionais dos professores e conhecimentos universitários: elementos para uma epistemologia da prática profissional dos professores e suas consequências em relação à formação para o magistério. Revista Brasileira de Educação, Rio de Janeiro, n. 13, p. 5-24, jan./abr. 2000. Disponível em: http://anped.tempsite.ws/novo_portal/rbe/rbedigital/RBDE13/RBDE13_05_MAUR ICE_TARDIF.pdf. Acesso em: 15 jan. 2021. 
UFMS - UNIVERSIDADE FEDERAL DE MATO GROSSO DO SUL. Campus de Três Lagoas. Licenciatura em História. Plano de educação mínima (PEM): aprovado pela Resolução n. 19, de 13 de julho de 2020. Três Lagoas: UFMS, 2020a. Disponível em: http://historiacptl.ufms.br/documentos/. Acesso em: 15 jan. 2021.

UFMS - UNIVERSIDADE FEDERAL DE MATO GROSSO DO SUL. Portaria N. 405, de 16 de março de 2020. Campo Grande: UFMS, 2020b. Disponível em: https://boletimoficial.ufms.br/bse/publicacao?id=389814. Acesso em: 15 jan. 2021.

Recebido em 18 de fevereiro de 2021 Aprovado em 05 de junho de 2021 